\title{
UM RASCUNHO PARA A SEMÂNTICA DE MUITO: EXPLORANDO A SEMÂNTICA DE DELINEAÇÃO*
}

\author{
ROBERTA PIRES DE OLIVEIRA ${ }^{1}$ \\ (UFSC-UFPR/CNPQ) \\ LUISANDRO MENDES DE SOUZA ${ }^{2}$ \\ (UFRGS)
}

\begin{abstract}
RESUMO: Este artigo inicia uma análise semântica para muito adverbial. Essa proposta estende a Semântica de Delineação (KLEIN, 1980; BURNETT, 2014; 2015) para o domínio dos eventos. A expressão muito $P$, em suas várias manifestações (modificando verbos, adjetivos ou nomes), é uma função que denota o conjunto contextualmente dado dos indivíduos ou eventos que estão na extensão positiva do predicado. A análise assume que há eventos na ontologia (PARSONS, 1990). A comparação com advérbios como a lot 'muito' (inglês) e beaucoup 'muito' (francês) mostra que esses modificadores compartilham leituras (frequência, duração e quantidade de objetos ou suas partições) e restrições. Com estados, esses advérbios produzem leitura de intensidade, porque estados são de-adjetivais e adjetivos ordenam os objetos em extensões positivas, negativas ou vagas. Explicamos as leituras e as restrições assumindo que muito pressupõe 'mais de um' (eventos, momentos no tempo, objetos ou porções de objetos), pois opera sobre um conjunto ordenado, dado contextualmente pela classe de comparação.
\end{abstract}

Palavras-chave: Semântica de Delineação; Modificação Verbal; Eventos.

* Os autores agradecem aos dois pareceristas anônimos pelos comentários, questionamentos e sugestões que nos ajudaram a melhorar diversos aspectos do artigo.

${ }^{1}$ Graduada em Letras e Mestre em Linguística pela Universidade Estadual de Campinas. Doutora em Linguística pela Katholieke Universiteit Leuven (Bélgica). Professora Titular no Departamento de Língua e Literatura Vernáculas do Centro de Comunicação e Expressão da Universidade Federal de Santa Catarina - Florianópolis (SC). Pesquisadora nível 1 do CNPq. ropiolive@gmail.com

${ }^{2}$ Licenciado em Letras (Português/Inglês) pela Faculdade Estadual de Filosofia, Ciências e Letras de União da Vitória (PR). Mestre e Doutor em Linguística pela Universidade Federal de Santa Catarina. Professor Adjunto do Departamento de Letras Clássicas e Vernáculas do Instituto de Letras da Universidade Federal do Rio Grande do Sul - Porto Alegre (RS). luisandro.mendes@ufrgs.br 
ABSTRACT: This paper proposes a semantic analysis for the adverbial muito 'a lot'. The proposal is drawn within the framework Delineation Semantics (KLEIN, 1980; BURNETT, 2014; 2015). Muito $P$, in its various manifestations (modifying verbs, adjectives and nouns), is a function which denotes in the context the set of individuals which are in the positive extension of the predicate. The analysis assumes an ontology with events (PARSONS, 1990). Comparison with adverbs like a lot (English) and beaucoup (French) shows that these modifiers share interpretations (frequency, duration and amount of individuals or its parts) and restrictions. Modifying states, these adverbs have an intensity interpretation. States are de-adjectival; gradable adjectives order the domain in positive, negative or vague (gap) extensions. We explain the interpretations and restrictions assuming that muito presupposes 'more than one' (events, time intervals, objects or parts of objects) since its domain is the ordered set of individuals contextually given by the comparison class.

Keywords: Delineation Semantics; Verbal Modification; Events.

$\mathrm{O}$ artigo apresenta o esboço de uma proposta para a semântica de muito adverbial no Português Brasileiro (PB) contemporâneo dentro do quadro de uma Semântica de Delineação (KLEIN, 1980; BURNETT, 2014; 2015). ${ }^{3}$ Embora a nossa proposta seja trans-categorial, atribuindo a muito uma semântica unificada nos vários domínios que ele percorre - adjetival, verbal e nominal - neste artigo, o foco é o que podemos chamar grosseiramente de muito-adverbial e que alguns autores (ILARI et alii, 1993) disseram ser um pronome indefinido, como exemplificado em (1). Argumentaremos adiante contra essa proposta:

\section{(1) A Maria comprou muito.}

A literatura sobre a semântica do muito no PB já disponível é bastante rica (GUIMARÃES, 2007; QUADROS GOMES, 2011; neste volume). Quadros Gomes (neste volume) também objetiva chegar a uma semântica única para os vários muito com os quais convivemos. Sua proposta é que muito indica grau não-máximo numa escala. Como nosso objetivo, neste artigo, é investigar o quanto conseguimos explicar os dados do PB com uma semântica sem graus, não iremos discutir a sua proposta.

Propomos que muito é um modificador que toma um predicado de indivíduos ou de eventos, $<\mathrm{e}, \mathrm{t}>$ ou $<\mathrm{ev}, \mathrm{t}>$ (em que ev representa eventos), e retorna o mesmo tipo semântico: um conjunto de indivíduos ou de eventos, $<<$ et $>,<$ et $>>$ ou $<<$ evt $>$, $<$ evt $>>$. Sua semântica é bastante simples; informalmente, ele denota a extensão positiva da extensão positiva de um predicado. Assim se alto significa estar na extensão positiva dos altos, ser muito alto significa estar na extensão positiva dessa extensão positiva. Este artigo concentra seu foco apenas no muito modificador de eventos; assim, assumimos que as análises para os adjetivos e os nomes, propostas por Klein $(1980 ; 1981)$ e Burnett (2016) estão na direção correta, isto é, não há graus na ontologia das línguas naturais.

\footnotetext{
${ }^{3}$ Estamos no momento trabalhando no sistema formal que não será apresentado neste artigo.
} 
A primeira seção apresenta os dados empíricos e investiga o muito adverbial comparado a a lot 'muito', no inglês, e a beaucoup 'muito', no francês. A interpretação de intensidade associada a essas expressões nos levará ao domínio adjetival e será o mote para expormos informalmente a Semântica de Delineação, tema da segunda seção. Essa semântica foi inicialmente projetada para resolver o problema dos adjetivos graduais como alto sem utilizar graus na ontologia, como faz Kennedy (1997; 2007; entre outros). Burnett (2015) estende essa semântica para o domínio do nominal e afirma que sua proposta pode ser estendida para o verbal, sem, no entanto, realizar essa tarefa. O centro deste artigo é a terceira seção, em que fazemos a nossa proposta para o domínio verbal e que, esperamos, explica os dados apresentados na primeira seção. Ela se ancora numa Semântica de Eventos (PARSONS, 1990) e tem como suporte a Semântica de Delineação. Trata-se de uma proposta original, já que, do que sabemos, não houve nenhuma tentativa de estendê-la ao domínio verbal. É preciso acrescentar, no entanto, que realizar esse empreendimento não é em si um argumento contra a semântica de graus, para tanto precisamos de argumentos empíricos.

\section{ELA DANÇOU MUITO: PRIMEIRAS EVIDÊNCIAS}

Se compararmos o Português Brasileiro (PB) a línguas como o inglês e o francês, com base em Doetjes (1997; 2007), notamos que tanto a distribuição das interpretações quanto as restrições são praticamente as mesmas, com exceção do que podemos denominar de leitura de 'qualidade', que parece estar disponível apenas para o PB e mesmo assim talvez apenas para alguns casos como (2c), em que se qualifica a dança do sujeito como sendo "muito boa":

(2) a. She dances a lot.

b. Elle dance beaucoup.

c. Ela dança muito. (frequência e duração)

(frequência e duração)

(frequência, duração e qualidade)

Retornamos à leitura de qualidade mais adiante. Por enquanto, basta notar que as sentenças em (2) podem ser interpretadas como uma grande quantidade de vezes em que ela dançou ou uma grande duração do evento de dança. Aparentemente essas interpretações acontecem independentemente do tempo-aspecto: Ela dançou muito ontem tem todas essas interpretações.

Há ainda uma interpretação de quantidade de objetos que parece motivar a proposta de que muito é, no exemplo em (1) acima, um pronome indefinido. ${ }^{4}$ Assim, (1) significaria que "a Maria comprou muitas coisas". Essa é também uma leitura possível para os exemplos em (2) - "ela dançou muitas danças” -, embora não seja proeminente. Essa é a leitura de quantidade. Há dois problemas com essa proposta: (i) ela não pode ser estendida aos outros usos de muito que

${ }^{4}$ Guimarães (2007) chama esse uso de muito de 'função argumental'. 
não são indefinidos, como com os estativos A Maria amou muito o João ou com adjetivos e nomes; (ii) a única maneira de explicarmos as diferentes leituras de (2c) é um sintagma encoberto cujo núcleo pode ser muitas coisas, muitas vezes, muito tempo, isto é, via ambiguidade. Nossa proposta é uma alternativa sem ambiguidade.

Esse curto percurso mostra que há diferentes interpretações que nem sempre estão disponíveis. A leitura de qualidade não parece ocorrer com (1), por exemplo. Pires de Oliveira, Basso e Souza (2007) descrevem as leituras permitidas pelo muito adverbial quando combinado com atividades e propõem que se trata de um caso de "indeterminação" semântica e não ambiguidade. Vamos explorar essa ideia neste artigo. Não é nossa intenção nem realizar um levantamento exaustivo das diferentes possibilidades de combinação de muito - com as classes acionais, com o aspecto gramatical, com diferentes tipos de advérbios, nem levantar as diferentes possibilidades e restrições de leitura. A semântica que iremos propor busca explicar os casos de restrição, derivando da necessidade de uma classe de comparação, logo, mais de um indivíduo. Se essa restrição é satisfeita, há várias possibilidades de leitura, como mostramos para (1) e (2c). Essa semântica permite que várias leituras sejam dadas. Iremos esclarecer essa ideia ao longo deste artigo.

A literatura afirma que advérbios como muito não se combinam com achievements. Sentenças como (3a), se aceitáveis, têm uma interpretação de repetição: "João chegou uma grande quantidade de vezes ao topo do Aconcágua". Quando combinado com accomplishments, (3b) e (3c), dão ensejo à interpretação partitiva, e as paráfrases seriam respectivamente: "João construiu muitas partes da casa"; "ela tricotou uma boa quantidade do suéter":
a. \# João chegou muito ao topo do Aconcágua.
(??frequência) $)^{5}$
b. \# João construiu muito a sua casa.
(??partitiva)
c. \# She knitted the sweater a lot.
(??partitiva)
d. \# Ela tricotou muito o casaco.
(??partitiva)

A literatura já dispõe de uma boa compreensão tanto sobre essas restrições quanto sobre essas leituras. Em (3a) temos um achievement no perfectivo. Estamos, portanto, diante de um predicado atômico num intervalo de tempo fechado. Se, como acreditamos, muito de alguma forma "compara", então, para isso, é preciso que haja mais de uma entidade na denotação do predicado sobre o qual muito opera. $\mathrm{O}$ perfectivo acoplado a um achievement indica um evento único e particular. Logo, estamos diante de um impasse, por assim dizer, e a sentença soa estranha. O mecanismo de restauração é encontrar outra entidade, por assim dizer. Se estendermos o tempo, através de advérbios de vida (MITTWOCH, 1988), a leitura de frequência fica facilitada - Durante a sua vida, ele chegou muito ao topo do Aconcágua. A

${ }^{5}$ Deixamos o símbolo '??' para indicar que essas leituras são disponíveis apenas via algum tipo de coerção. À primeira vista as sentenças são anômalas, o que indicamos usando '\#'. 
estratégia de reparação é pluralizar eventos de um mesmo tipo: foram vários eventos de chegar ao pico. A leitura de duração não ocorre porque achievements não têm duração temporal relevante; são predicados instantâneos, embora possam envolver uma fase preparatória. Mas não se exclui uma leitura em que sua aproximação do ponto máximo ocorreu: ele ficou cada vez mais perto do cume.

A restrição em (3b) é da mesma ordem daquela de (3a), modificadores como muito comparam, logo, é preciso mais de uma entidade (seremos mais explícitos adiante). Em (3b) temos um accomplishment no perfectivo que indica que a casa foi construída, que há uma casa pronta, e o evento está finalizado. Trata-se mais uma vez de um evento em particular. A leitura de frequência parece ser pragmaticamente suspensa mesmo com os advérbios de vida porque em geral não se constrói a mesma casa várias vezes. Neste caso, a estratégia de reparação parece ser particionar o objeto e medir o quanto do objeto foi criado. Além dessa, a leitura de "foi responsável pelo pagamento de mais porções da casa" parece ser acionada por alguns falantes.

Os degree achievements, como em (4), já foram discutidos e tratados como de-adjetivais, vindos de adjetivos e comportando, portanto, ordenações em uma escala (KENNEDY; LEVIN, 2007): (4a) indica que o nível do rio subiu e (4b) que houve um avanço na escala do ser gordo. ${ }^{6}$ Estamos diante de escalas como nos adjetivos graduais, como alto, que iremos discutir na próxima seção.
a. O rio subiu muito.
(escalar, frequência) $)^{7}$
b. Ele engordou muito.
(escalar, frequência)

Mais uma vez as possibilidades de leitura parecem condicionadas pelas possibilidades dadas pelo predicado. Embora tanto (4a) quanto (4b) tenham preferencialmente leitura de grau do nível do rio ou da gordura de João, elas permitem leitura de frequência - ele engordou muito durante a vida, parece permitir também a leitura de número de vezes em que ele engordou. Degree achievements são escalares, isto é, eles sempre particionam o domínio em escalas, mas são também processos que podem ser tomados em unidades e, portanto, contados.

As sentenças de $(5 a)$ a $(5 c)$ comparadas a $(5 d)$ mostram que o português parece se comportar como o francês: a combinação com predicados accomplishment, que são atômicos, produzem sentenças marcadas, como já vimos nos exemplos em (3), mas que em contexto podem receber uma leitura mediante algum tipo de mudança na interpretação, quer via partição de um objeto (leitura partitiva), quer via sub-eventos de leitura de um livro definido, quer via repetição de eventos do mesmo livro:

\footnotetext{
${ }^{6} \mathrm{Na}$ leitura atélica, a sentença declara que João avançou na escala de peso, sem acarretar que ele esteja agora no grau positivo de gordo - pode ser o caso que ele ainda esteja magro. Na leitura télica, pode-se inferir que João está gordo, e muito, em tese, mediria o quanto o indivíduo avançou na escala de peso.

${ }^{7}$ Subir é um verbo, mas Basso e Ilari (2004) mostram que esse verbo também envolvem aproximação gradual de uma meta e $O$ rio subiu pode ser parafraseado por algo como "o rio está mais alto".
} 
(5) a. \#João leu muito o seu livro.

b. \#João escreveu muito a sua tese.

c. \#João cozinhou muito essa carne.

d. \#Jeanne a beaucoup écrit la lettre. (frequência, partitiva, \#duração)

(\#frequência, partitiva)

(duração, frequência) ${ }^{8}$

(DOETJES, 2007)

Como estamos vendo, muito parece coagir facilmente predicados singulares a se tornarem pluralizados. Em (5b) é a natureza do objeto, um tema incremental, que bloqueia a leitura de frequência, o que faz com que, via coerção, tenhamos a leitura partitiva, mesmo que não soe tão boa quanto em $(5 \mathrm{a}) \cdot{ }^{9}(5 \mathrm{c})$ permite leitura de frequência se essa carne for interpretada como esse tipo de carne (BASSO; PIRES DE OLIVEIRA, 2015). ${ }^{10}$

Aparentemente, a restrição de gramaticalidade deriva da própria semântica de muito, que exige mais de uma entidade (mais sobre isso adiante). As estratégias de restauração envolvem definir um domínio de comparação que disponha de uma ordenação, o que exige mais do que uma entidade: as partes do objeto, as instanciações de eventos-tipo, instantes no tempo... As restrições de leitura se explicam por vários fatores, incluindo o nosso conhecimento sobre como os eventos ocorrem no mundo.

Interessantemente, a pluralidade é condição necessária, mas aparentemente não é suficiente para explicar a restrição em (6), supondo que ela exista:

(6) ?? João construiu muito casa (a vida toda).

(6) deveria ser uma sentença aceitável, supondo que o predicado construiu casa é de alguma maneira interpretado como mais de um evento de construção de casa ou mais de uma casa, como é o caso em João construiu casa a vida toda. No entanto, ao menos para alguns falantes, a sentença produz ruído, por assim dizer. Comparando (6) com (7a) e (7b), percebemos que o problema não é exatamente a impossibilidade de muito aparecer entre o verbo e seu objeto. (7b) expressa que houve muitos eventos de um tipo específico de construção: a de casa (e não de prédios, por exemplo). Claro, (7c) parece-nos a forma mais comum de expressar esse conteúdo:

(7) a. O João construiu muito apartamento.

b. Casa, o João construiu muito.

c. O João construiu muita casa (na sua vida).

\footnotetext{
${ }^{8}$ A leitura de que "João cozinhou a carne mais do que devia", parece ser uma implicatura, afinal, se a duração do cozimento foi longa, o ouvinte pode inferir que a carne passou do ponto. Note que podemos negar essa inferência:

O João cozinhou muito essa carne, mas ela não passou do ponto, felizmente.

O João cozinhou muito essa carne e ela ficou maravilhosa.

${ }^{9}$ Pelo menos é essa a intuição de um dos pareceristas.

${ }^{10}$ A leitura intensional do nome coloca inúmeros problemas que não podemos tratar neste artigo. Em particular, estamos falando também de um evento tipo, que enquanto tal, deve ser um accomplishment.
} 
A hipótese é de que a adjacência de muito com um nome que carrega os traços de gênero torna a sentença agramatical porque esse traço precisa ser checado. $\mathrm{O}$ falante consegue interpretar se re-analisar sintaticamente muito como um advérbio de sintagma verbal, voltamos a esse ponto mais adiante. O movimento em (7b) mostra que não há relação de constituinte entre muito e casa no uso adverbial. Nesse uso, a única leitura é de tipo de construção, o esperado se de fato o singular nu no PB denotar a espécie (PIRES DE OLIVEIRA, 2014; entre outros). Em sentenças como $O$ João ama muito a irmã, não há possibilidade da interpretação de adjacência; logo, só há leitura de modificação do sintagma verbal. Na nossa proposta (7a) é ambígua podendo ser analisada sintaticamente como modificação do nome ou do sintagma verbal. Note que se muito for um adjunto do sintagma verbal, a estrutura com muito determinante se torna homofóna daquela, assumindo que o verbo se mova para as projeções funcionais acima de seus adjuntos baixos para checar traços da morfologia verbal.

A literatura reporta ainda a leitura de intensidade para a modificação de estados (DOETJES, 1997; entre outros) realizada pelos advérbios que estamos estudando, como nas sentenças em (8):
a. She loves him a lot.
(intensidade)
b. Elle lui ame beaucoup.
(intensidade)
c. Ela ama muito ele.
(intensidade)

$\mathrm{Na}$ nossa proposta, as restrições de leitura não são da ordem da checagem de traços, mas estão atreladas ao sentido do item lexical, sendo, portanto, de ordem mais enciclopédica do que gramatical, propriamente falando. A única restrição gramatical é a interpretação estar associada a uma classe de comparação, o que exige mais de uma entidade. A intensidade não se restringue a predicados de estado. Predicados psicológicos como assustar também tem leitura de intensidade. Descrevendo informalmente, há escalas de sentimentos, de amor e ódio (sem pontas máximas, afinal, os verbos são atélicos), de susto, de gosto e por aí a fora. Assim, estados denotam propriedades escalares, como ocorre com os adjetivos graduais como alto ou cheio. (8c) expressa que o seu sentimento de amor por ela está acima do amor médio. Note que os estados são não-dinâmicos, mas tem duração temporal, cf. Ela amou ele por dois anos, por isso a leitura de duração também pode ser acionada.

Ainda, alguns estados parecem permitir leitura de frequência, além da de intensidade e de duração. O mesmo ocorre com o inglês (10). A leitura de frequência com os estativos verbais parece atrelada à possibilidade de termos repetição do estado. O estranhamento da leitura de frequência em (9a) é pragmática e disparada pelo intervalo de tempo considerado: não é normal adoecermos e sararmos no mesmo dia. Se o intervalo de tempo for ampliado, como em (9b) e (9c), temos a leitura de frequência:

(9) a. Fiquei muito doente ontem.

(??frequência/intensidade)

b. Fiquei muito doente mês passsado. (frequência/intensidade)

c. Fiquei muito doente ano passado. (frequência/intensidade) 
(10) a. I've been sick a lot lately.

(frequência, intensidade, duração)

b. I have headaches a lot.

(frequência)

A leitura de intensidade não se confunde com a de qualidade de (2c). Se a Maria dançou muito é porque ela foi uma ótima dançarina, seu desempenho a colocou entre aqueles que dançam bem. Essa interpretação parece bastante restrita. Ela não ocorre com todas as atividades, embora ser uma atividade pareça necessário. Achievements e accomplishments não permitem tal interpretação, como é possível verificar tentando atribuir tal leitura para vários dos exemplos acima. Uma possibilidade, que vamos sugerir, é que a leitura de qualidade teria, na sua estrutura lógica, subentendido um advérbio como bem, porque ela parece exigir uma curva prosódica particular que pode assinalar algum material elidido.

Nessa seção apresentamos os dados e descrevemos informalmente algumas restrições de leitura. Nosso objetivo final é explicar esse quadro. $\mathrm{Na}$ próxima seção apresentamos a Semântica de Delineação, que foi inicialmente proposta para descrever os adjetivos graduais e a comparação (KLEIN, 1980; BURNETT, 2014) e posteriormente estendida para a comparação nominal de quantidade (KLEIN, 1981; BURNETT, 2015). Vamos amparar a nossa semântica do muito adverbial nessa reflexão.

\section{ELA DANÇOU MUITO BEM: UMA BREVE INTRODUÇÃO À SEMÂNTICA DE DELINEAÇÃO}

Como já dissemos, há duas grandes correntes para interpretação dos adjetivos graduais, como (11a) abaixo, e não é nosso objetivo fazer essa revisão teórica: a Semântica de Graus, que entende que há graus na ontologia, e alternativas que não aderem à ideia de graus. Klein (1980) é talvez o marco da abordagem sem graus, embora ela tenha sido originalmente proposta por Kamp (1975). A hipótese central é que adjetivos são predicados como quaisquer outros, tipo $<$ e,t $>$, funções de indivíduos a valores de verdade. ${ }^{11}$ Uma crítica que aparece em Kennedy (2007) é que essa proposta não conseguiria distinguir adjetivos relativos como alto, que são vagos e possuem parâmetro relativo (ou contextual), de adjetivos absolutos como cheio, que não são vagos e possuem parâmetro lexical (ou natural). Burnett (2014) mostra que essa crítica não se sustenta: se for preciso distinguir adjetivos relativos e absolutos, é possível fazer isso numa semântica sem graus. ${ }^{12}$ Mais uma vez não é nosso objetivo levar adiante essa discussão.

(11) a. John is tall.

b. John is taller than C.

${ }^{11}$ Numa semântica de graus, adjetivos graduais costumam ser tratados como funções de graus a indivíduos a valores de verdade: $<\mathrm{d},<\mathrm{et}>>$.

${ }^{12}$ Burnett (2014) é uma proposta de análise dos adjetivos graduais, incluindo os absolutos, dentro de uma semântica de delineação, em conjunto com uma teoria de vagueza que quer lidar com o fenômeno da imprecisão. Como nosso foco não é a semântica dos adjetivos, não aprofundaremos essa discussão. 
Onde C é um padrão de comparação cujo valor é dado contextualmente.

Klein quer manter a intuição de que (11b) é a estrutura mais complexa. No quadro da Semântica de Graus, (11a) tem a forma lógica em (11b), ou seja, João é alto significa "João é mais alto que um grau de referência". Klein entende que essa análise fere o princípio da Composicionalidade. Em sua proposta, a forma lógica de (11a) não é (11b). Para Klein, o adjetivo, porque é vago, particiona o domínio em indivíduos que são altos (a extensão positiva), indivíduos que são baixos (a extensão negativa) e indivíduos que não são nem altos nem baixos (a lacuna extensional). Assim, embora tall seja uma função de tipo $<\mathrm{e}, \mathrm{t}\rangle$, adjetivos graduais são funções parciais porque há contextos em que seremos incapazes de dizer para alguns indivíduos se é verdadeiro ou falso que eles possuem a propriedade. Como a semântica é de delineação, (um modo de "precisificar", tornar preciso), é possível arbitrar um critério de tal sorte que tenhamos uma função total que particiona o domínio em altos e baixos. A função é total se considerarmos o domínio inteiro.

Na forma lógica de (11a) não há, portanto, um lugar para a variável de graus; a classe de comparação é dada contextualmente. Se o contexto muda, a classe de comparação muda e conseguimos entender como (11a) pode ser verdadeira em um contexto e falsa em outro sem que a altura do John mude. Eis a proposta para a forma lógica de (11a) a partir de Klein (1980):

(12) $[[\text { John is tall }]]^{\mathrm{C}}=1$ se e somente se o João estiver na extensão positiva de alto em C.

Suponha que no contexto a classe de comparação seja o conjunto dos jogadores de basquete da NBA, cuja altura média é 2 metros, e que João, um jovem talentoso armador recém-recrutado por um time da liga, possui $1,80 \mathrm{~m}$ de altura. Nessa situação, a sentença é falsa, porque o jogador de basquete médio é mais alto do que o jogador brasileiro (ou seja, o corte para ser considerado alto será $2 \mathrm{~m}$ de altura). Para Klein, o que define a classe de comparação pode ser aquele conjunto de entidades salientes no discurso, ou o tópico discursivo, do que estamos falando naquela situação. Suponha outro contexto em que a classe de comparação seja formada por crianças de 10 anos, com altura média de $1,60 \mathrm{~m}$, e que João é um menino de $1,65 \mathrm{~m}$. Agora a sentença é verdadeira. Note que para uma sentença como $x$ é alto ser verdadeira, não depende das propriedades físicas de um indivíduo, representado por $\mathrm{x}$, mas sim de que modo ele se situa dentro da classe de comparação (e qual é o corte, digamos assim, da classe). A posição dos indivíduos é fixa na ordenação dos objetos na ontologia, o que muda é classe de comparação, que é uma função parcial, isto é, delimita contextualmente uma região do modelo. Dessa forma, Klein (1980) assume que um adjetivo como tall pressupõe um ordenamento do domínio em relação à classe de comparação e ao padrão para ser considerado alto no contexto, e segmenta o domínio no contexto em: a extensão positiva de alto; a extensão negativa de alto; e a lacuna extensional de alto no contexto (caso haja alguma). Esse é um aspecto importante: na classe de comparação de tall temos indivíduos que estão abaixo do padrão de tall na situação. Suponha que o nosso conjunto de indivíduos seja o seguinte: \{Pedro, 
Irineu, João, Nelson, Marcos\}. A função irá ordenar os indivíduos dentro do domínio. Suponha que o padrão é $1,70 \mathrm{~m}$ e que as alturas sejam: Pedro, $1,30 \mathrm{~m}$, Irineu, 2m, João, 1,80m, Nelson 1,65m e Marcos, 2,10m. Essa função irá retornar, tendo em vista o padrão contextual, uma ordenação em três conjuntos: os altos, os nem altos nem baixos, e os baixos: $\{\{$ Marcos, Irineu, João $\},\{$ Nelson $\},\{$ Pedro $\}\}$, onde Nelson está na lacuna, Pedro é baixo, e Marcos, João e Irineu são altos.

Considere agora a entrada lexical para very:

(13) $[[\text { very } \mathbf{A}]]^{\mathrm{C} / \mathrm{X}}=[[\mathbf{A}]]^{\mathrm{C} / \mathrm{X}}=$ o conjunto $\mathrm{X}$ daqueles indivíduos que estão na extensão positiva de A em C. (KLEIN, 1980, p. 25)

Note que very se aplica à extensão positiva de $A$, considerando a classe de comparação X. Logo, a classe de comparação é a extensão positiva de $A$ : o very leva para o alto dentro dos altos. Assim, ser very tall é estar na extensão positiva da extensão positiva de tall, o que eleva o padrão, já que só são considerados os indivíduos que são altos. Isso explica o efeito de alçamento de padrão que vemos com o very (e os intensificadores em geral). Enquanto o domínio de tall inclui aqueles que também não são altos, o domínio de very tall olha somente para os que são altos (ou seja, a classe de comparação é mais restrita), o que dá conta do fato de podermos ter dentro do conjunto dos altos indivíduos para quem a declaração $x$ é muito alto será falsa. No nosso exemplo, very organiza a conjunto dos altos \{Marcos, Irineu, João\}, em altos positivos, nem no positivo nem no negativo, e altos negativos: $\{\{$ Marcos, Irineu $\},\{J o a ̃ o\}\}$. Assim, João não é muito alto, mas é alto nesse contexto.

Neste tipo de proposta, a ontologia é uma estrutura ordenada, i.e., os indivíduos estão organizados dentro do domínio em função de uma ordenação dada pela propriedade (no caso acima, do mais alto para o mais baixo), assim a linguagem não precisa se preocupar com isso. Já a metalinguagem precisa e é isso exatamente o que Klein e Burnett fazem com mestria. Klein (1981) e Burnett (2015) expandem, construindo diferentes aparatos formais, essa análise dos adjetivos para o domínio dos nomes e para a semântica de much/many. Much/ many e very são formas distintas de expressar o mesmo conteúdo em domínios ontológicos distintos, mas cuja estrutura é também ordenada. Afinal, ordenamentos constroem escalas, somas, mereologias, todos e partes, reticulados, estruturas lógicas (LANDMAN, 2000).

No tratamento de much/many, Burnett (2015) se ampara na proposta de Bale \& Barner (2009) para os nomes no inglês. Para esses autores, a denotação do nome raiz é massiva. Há uma operação de identidade para os nomes de massa e uma de atomização para os nomes contáveis. Como já é tradição na semântica, os nomes organizam a ontologia em (semi)reticulados, que são mereologias de somas (com as propriedades que caracterizam a soma enquanto pluralidade, que não se confundem com a soma matemática, cf. Krifka, 1990). Grosseiramente, tanto a raiz book quanto water denotam um semi-reticulado não atômico fechado em soma, mas apenas book pode ser pluralizado em books, porque foi atomizado na sintaxe, de acordo com os autores, ou no léxico para autores como Rothstein (2017). Assim explicamos a distribuição de many e much no inglês: 
(14) a. John bought many books.

\section{O João comprou muitos livros.}

b. John drunk much water.

O João bebeu muita água.

Há muito a ser dito sobre as sentenças em (14), mas nosso objetivo é apenas esboçar como é possível um tratamento unificado para os nomes e os adjetivos. Na Semântica Formal contemporânea, no mundo objetos e substâncias se organizam em somas, os reticulados, que são estruturas de "x mais y": um indivíduo (e o próprio indivíduo resulta no indivíduo (KRIFKA, 1989)), um indivíduo mais um indivíduo. O domínio das coisas e das substâncias se ordena em quantidades maiores, em somas de quantidades até a soma máxima, que são todos os objetos no mundo. A diferença é que books é um reticulado atômico, logo, as unidades mínimas são átomos que não podemos decompor - um pedaço de livro não é um livro; ao passo que água não tem átomos e pode ser particionada indefinidamente (ao menos do ponto de vista da linguagem). Assim nomes denotam quantidades que estão ordenadas. É importante ter em mente que estamos numa semântica que lida com vagueza. O movimento assume que a vagueza é do sistema como um todo (por assim dizer).

Assim como com os adjetivos como alto, o que conta como "grande quantidade" é dependente do contexto, isto é depende da classe de comparação que está sendo acionada na interpretação. Se tenho 300 livros, tenho muitos livros se a comparação é com o brasileiro médio; mas tenho pouquíssimos livros se comparado com a Biblioteca Nacional. Many é uma função do semireticulado atômico em somas que já são "muito" no contexto, ou seja, estão na extensão positiva do nome. Much faz exatamente a mesma operação no domínio não-atômico: Tomei muita cerveja ontem pode ser verdadeiro mesmo que o falante tenha tomado um copo de cerveja (supondo que o falante não costume beber, um copo para ele já contará como "muito").

É possível que a proposta de Bale \& Barner (2009) não descreva o sistema nominal do PB (ver ROTHSTEIN; PIRES DE OLIVEIRA, 2011). A expectativa, incorreta, dessa proposta se aplicada ao PB, é que (15a) só poderia ser interpretada como pedaços de revista; já que revista é um nome contável singular. Esse certamente não é o caso do PB. (15a) permite leitura contável, inesperada pelo modelo de Bale \& Barner (2009) para predicados singulares. (15a) no PB pode ser verdadeira se João leu uma ou várias revistas ou pedaços de revista (MÜLLER, 2002). Muito cobre tanto many quanto much, pois não faz distinção entre nomes massivos ou contáveis: ${ }^{13}$

${ }^{13}$ Para uma descrição sobre a comparação nominal no PB ver Pires de Oliveira \& Souza (2013), entre outros. 
(15) a. João leu muita revista, enquanto esperava ser atendido.

b. João bebeu muita água, enquanto esperava ser atendido.

Já (15a) apresenta leituras que no inglês não são possíveis por causa precisamente da obrigatoriedade de optar por much ou many. ${ }^{14}$ Seja como for, os objetos estão ordenados em quantidades (vagas), massivas para Burnett (2014). ${ }^{15}$ Logo, o muito/a está realizando a mesma operação que many/much em inglês.

O muito determinante, diferentemente do que ocorre com o adverbial, dispara concordância e pode se combinar com o morfema de plural se o nome for contável: João leu muitas revista $(s)$. Não é nosso objetivo neste artigo apresentar a semântica do muito determinante, nem discutir a sua distribuição no PB. É suficiente ilustrar como a proposta para os adjetivos graduais pode ser estendida para os nomes de modo que temos uma explicação uniforme para (14a) e (11) no inglês, com os itens impondo seleções categoriais ou lexicais: many seleciona nomes contáveis, much seleciona nomes massivos e very seleciona adjetivos. A hipótese é que esses itens executam a mesma operação: denotam um subconjunto da classe de comparação que é a extensão positiva do predicado. A grande vantagem dessa proposta, no nosso entendimento, é que podemos tratar tanto alto quanto books ou water como predicados do mesmo tipo, conjuntos de indivíduos e derivar composicionalmente very tall de tall e many books de books.

Se books denota o reticulado, já temos uma ordenação de soma, portanto, de quantidade. Muito denota o subconjunto dos que são muito dentro do conjunto dos indivíduos, cuja soma conta como "muitos indivíduos" no contexto. Isso fica explícito nas denotações abaixo. Livros particiona o domínio em extensão positiva, neutra e negativa de quantidades, como representado em (16a). Muito toma a extensão de quantidade positiva e devolve o positivo dessa extensão:

(16) a. $[[\text { livros }]]^{\mathrm{C}}=\{\{\mathrm{a}+\mathrm{b}+\mathrm{c}+\mathrm{d} ; \mathrm{a}+\mathrm{b}+\mathrm{c}\},\{\mathrm{a}+\mathrm{b}, \mathrm{a}+\mathrm{c}, \mathrm{b}+\mathrm{c}\},\{\mathrm{a}, \mathrm{b}, \mathrm{c}\}\}$

b. $[[\text { muitos livros }]]^{\mathrm{C}}=\{\mathrm{a}+\mathrm{b}+\mathrm{c}+\mathrm{d}\}$

Veja que na nossa visão essa será a contribuição semântica do muito: retornar aquele conjunto de indivíduos, proporcionado pela classe de comparação, que conta positivamente como muito naquela situação. Assim, não são todas as somas possíveis do domínio que contarão como positivamente muito na situação. Desta forma, podemos ter indivíduos dentro do domínio para quem será falso que eles contem como muito (e.g.: a e b em (16a) estariam na extensão negativa de muitos livros).

\footnotetext{
${ }^{14}$ Sobre a interpretação dessas estruturas Bevilaqua \& Pires de Oliveira (2014).

${ }^{15}$ Essa ideia é recorrente em muitos autores. Krifka (1989), Chierchia (1998), Rothstein (2010).
} 
Comparativamente, a alternativa de graus, proposta a partir de Kennedy, tem dificuldades para explicar os exemplos em (14), embora seja possível postular que há uma variável de graus também para os nomes. ${ }^{16} \mathrm{O}$ problema com essa saída é que Kennedy é bastante parcimonioso com os graus, eles ocorrem apenas nos predicados graduais e books ou water não têm a propriedade de gradualidade. Sob esse ponto de vista parece mais econômico adotar uma proposta que não tem graus na ontologia, mas assuma que o domínio é estruturado em somas.

Nas páginas finas de seu artigo programático, em que ela estende a Semântica de Delineação para os nomes, Burnett (2015) afirma que seu modelo pode ser estendido para o domínio verbal, mas ela mesma não realiza esse movimento. Acreditamos que de fato é esse o caso e nosso objetivo neste artigo é esboçar como isso é possível. Já adiantamos que essa é a nossa proposta, com a qual talvez Burnett não concorde.

\section{ELA DANÇOU: O DOMÍNIO VERBAL}

Na seção 1, comparamos muito com a lot. Mostramos que as leituras suscitadas por muito adverbial são sensíveis a vários fatores e que no PB é possível uma leitura qualitativa que não ocorre no inglês. Nessa seção abordamos inicialmente as leituras adverbiais de muito que são também compatíveis com $a$ lot em inglês. Em seguida, sugerimos uma explicação para a leitura de qualidade.

A sentença (2c), repetida em (17) por conveniência, gera leituras de duração no tempo, parafraseada em (17a) e de frequência de eventos, parafraseada em (17b):

(17) João dançou muito.

a. "João dançou por muito tempo".

(duração)

b. "João dançou muitas vezes/músicas/danças"

(frequência)

Essas leituras também estão disponíveis para o a lot em inglês e para o beaucoup em francês (cf. DOETJES, 2007). A leitura de duração exige que estejamos falando sobre um evento; enquanto que a de frequência expressa que houve mais de um evento. Em quaisquer desses casos há uma pluralidade: ou de momentos de tempo, ou de vezes, o que satisfaz a pressuposição de comparação em muito. A nossa hipótese, inspirada em Klein, assume que (17) é composicionalmente derivada de (18):

(18) João dançou.

${ }^{16}$ Pires de Oliveira e Souza (2013) mostram que se pode assumir uma função de medida não pronunciada na comparação de quantidade que 'mede' a cardinalidade/volume das entidades na denotação do nominal. 
A maneira mais econômica de descrever a semântica de (18) é entender que não temos eventos na ontologia e que verbos são predicados de indivíduos como alto ou mesa. Essa é uma descrição compatível com a proposta de Montague para os advérbios e que Parsons (1990) critica. Parsons argumenta convincentemente que há eventos na ontologia, como havia sugerido Davidson (1967). Hoje em dia parece ser consensual na literatura contemporânea em semântica que há eventos. ${ }^{17}$ Suponha que seja esse o caso: verbos denotam conjuntos de eventos (ou eventualidades para cobrir os estados). Suponha também que adotamos uma semântica Neo-Davidsoniana e que a forma lógica de (18) está em (19) - vamos ignorar a contribuição dos morfemas temporais, embora ele esteja representado na forma lógica por $e<M F$ : "o evento antecede o momento de fala".

\section{(19) $\exists$ e [Dança (e) $\wedge$ Agente $(e, j) \wedge e<M F]$}

Com isso dizemos que "houve pelo menos um evento de dança cujo agente foi João e o evento foi anterior ao momento de fala". Assim (18) é verdadeira se estamos falando de um ou de mais de um evento. Suponha que na ontologia eventos se organizam em reticulados (KRIFKA, 1989; ROTHSTEIN, 2017) via soma de eventos. Considere também que o predicado TEMPO é uma função homomórfica ao desenvolvimento de um evento como Krifka (1989) propõe. Assim, há um tempo do evento, representado por $T(e)$ e esse tempo está em correspondência com o desenvolvimento do evento:

(20) $\exists$ e [Dança $(e) \wedge$ Agente $(e, j) \wedge T(e)<M F]$

Eventos se estruturam em somas e em eventos máximos e em mereologias de partes do evento que estão em correspondência com momentos no tempo. Particionamos os eventos em subeventos que se desenvolvem no tempo. A ontologia é assim altamente ordenada. Dar o laço inicial da linha na agulha de tricot é um sub-evento de um evento (virtual) de ter um suéter tricotado. Dançar é talvez mais vago, já que é mais inexato determinar o que podemos contar como um evento de dança, mas suponha que sabemos o que marca o início de um evento de dança, podemos então contar o tempo de duração desse evento. ${ }^{18}$ Se determinarmos o que é um átomo de dança, um evento completo de dança ou do tricote de um suéter, podemos contar. Note que estamos mais uma vez lidando com a vagueza: o que conta como um evento de dança é vago. O que é um evento de construção de uma casa também. Se determinarmos que há um evento, existe um tempo do evento, e podemos contar os eventos. Eventos se desenvolvem no tempo e podem ser contados. Há uma correspondência entre sub-eventos e tempos, garantida por um isomorfismo ontológico.

\footnotetext{
${ }^{17}$ Veja Chierchia (2003) para um resumo dos argumentos a favor de eventos.

${ }^{18}$ Veja a discussão de Landman \& Rothstein (2012) sobre dançar uma valsa.
} 
Rothstein (2017) abandona a ideia, cuja origem parece ser Bach (1986), de que há uma correspondência entre nomes e verbos. A autora argumenta que verbos denotam massivamente como os nomes de massa atômicos, por exemplo, furniture. Seja como for, eventos são organizados em somas e em mereologias (sub-partes de um evento).

Para efeitos de análise sintática, vamos supor que muito seja adjunto do sintagma verbal. Suponha ainda que papéis temáticos são atribuídos no sintagma verbal que irá então denotar um conjunto de eventos. Esses eventos vão estar ordenados por algum padrão dado pelo contexto. Muito tem como seu domínio o conjunto positivo de um conjunto de eventos ordenados num contexto e retorna um conjunto de eventos ordenados. Assim, sabemos que os eventos de dança de João são ordenados por um padrão e estamos falando da extensão positiva desse ordenamento. Muito toma essa extensão positiva e ordena novamente. Assim a dança de João está no positivo do positivo de uma ordenação de eventos de dança. A classe de comparação pode ser então as atividades de dançar realizadas pelo João ordenadas por quantidade (como nos nomes) ou ordenadas pelo tempo de duração. Suponha que muito modifica o evento, Muito(e):

$$
[[\exists e[\text { Dança }(e) \wedge \text { Agente }(e, j) \wedge T(e)<M F \wedge \operatorname{Muito}(e)]]]^{C}
$$

Muito adverbial pressupõe um conjunto ordenado de eventos. Em (17) essa pluralidade ("mais de um") é dada por mais de um evento de dança em que o protagonista foi o João comparados por algum padrão. O pretérito perfeito direciona para a leitura de um evento de dança. Esse evento é comparado a outros eventos. Suponha que a conversa é sobre quem dançou muito tempo ontem na festa. Os eventos estão ordenados na escala do tempo dado por algum padrão. Se a escala for de quantidade de vezes ou de qualidade da dança é dado pelo fundo conversacional compartilhado. Eventos sem duração no tempo, como os achievements, não vão permitir leitura de duração no tempo. Accomplishments no perfectivo denotam eventos particulares, únicos, e por isso sua combinação com muito é marcada. Há, no entanto, maneiras de restituir uma interpretação, provavelmente via coerção, que é particionar o objeto (CHIERCHIA, 2010) ou intensionalizando o objeto para podermos ter instanciações do objeto e, portanto, diferentes eventos.

Acreditamos que com algum trabalho de maquinaria chegamos às diferentes interpretações de (17), expressas em (a) e (b). Note que muito não modifica nem o evento nem qualquer dos componentes, o tempo do evento por exemplo. É a classe de comparação que leva a uma leitura ou a outra. A contribuição de muito é impor que haja uma classe de comparação de eventos, quando ele modifica o verbo. Até que seja acionada a classe de comparação no momento do proferimento, se a pressuposição estiver satisfeita, não há como saber qual é a dimensão da comparação: se estamos falando da quantidade de eventos ou da duração dos eventos. Veja que a interpretação de duração, em (17a) não se deve a uma modificação na duração do evento. O raciocínio não é esse. A sentença em (17) permite diferentes classes de comparação de eventos de João dançar. Esses eventos podem ser comparados via quantidade ou via duração dos eventos. A melhor paráfrase para (17a) é: eventos de dançar se estruturam em duração no tempo, muito seleciona os mais demorados naqueles que já são demorados. 
Assim, [[muito $\mathrm{V}]]^{\mathrm{C} / \mathrm{X}}$ denota a extensão positiva de uma partição dos eventos (quantidade, duração):

(21) $[[\text { muito } \mathrm{V}]]^{\mathrm{C} / \mathrm{X}}=[[\mathrm{V}]]^{\mathrm{C} / \mathrm{X}}=\mathrm{o}$ conjunto $\mathrm{X}$ na extensão positiva de $\mathrm{V}$ em $\mathrm{C}$.

A proposta é estritamente kleiniana, embora estendida para os eventos e há muito ainda a ser esclarecido.

A sentença em (1) permite a leitura de "muitas coisas", como vimos. Nesse caso, a classe de comparação pode ser a quantidade de eventos, mas também a quantidade de coisas que são compradas. Eventos de compra são instantâneos, logo a leitura de duração está suspensa, porque todos os eventos têm a mesma duração (já que são instantâneos).

Se a adjunção ocorre acima do aspecto, então se o aspecto é perfectivo e o evento tem um final, é télico, estamos diante de um conjunto unitário e a sentença não é feliz, como é o caso das sentenças em (3) e em (5). Accomplishments no perfectivo com um objeto único, isto é, com artigo definido, denotam um evento em particular não são felizes com muito porque a classe de comparação é um único conjunto de um único evento. A pressuposição de haver uma ordenação não está satisfeita, porque algo não pode ser mais ordenado que aquele mesmo algo. Logo, a combinação não funciona por razões semânticas. Considere João cozinhou muito essa carne. Em geral, não é possível que uma mesma porção de carne seja cozida mais de uma vez. O mesmo vale para João construiu muito a sua casa, já que a rigor não é possível construir a mesma casa mais de uma vez. Porque accomplishments são télicos, a leitura de repetição de eventos está bloqueada porque não é possível fazer algo que já está feito, por assim dizer. A leitura de tempo de duração também não é possível porque só dispomos de um único evento que tem a sua duração já dada. Não há como comparar. O mesmo vale para Maria tricotou muito o suéter.

Como já indicamos, uma forma de restaurar é particionar o objeto e/ou o evento. Entendemos que esse é um mecanismo de coerção e, portanto, deve aparecer algum efeito dessa natureza se experimentos de processamento semântico forem realizados. Se houver reparação, é preciso particionar o objeto. Particionar o objeto é também, dados os isomorfimos, particionar em subeventos. No primeiro caso, a comparação é a classe das partes do objeto organizadas em mereologias. No segundo, a comparação são os sub-eventos do evento télico. Logo, o evento é interpretado como estando em progressão e seu telos não foi alcançado.

Uma outra possibilidade de reparação, que também deve ser custosa, é interpretar intensionalmente, o que nos permitiria instanciações do mesmo tipo e levaria a uma leitura intensional do evento. Esse parece ser o caso de \#Ela trouxe muito o bolo para as nossas reuniões. Ou seja, nesse tipo de predicado o objeto não pode ser um token, pois ele delimitaria o evento, que seria, então, um predicado singular e a interpretação fica comprometida porque não é possível ter o mesmo bolo. Se realizamos uma operação para a espécie, temos uma classe de comparação: trata-se de eventos em que o João trouxe o tipo bolo e não trouxe outro tipo. Há muito a ser dito aqui e não podemos nos estender. Esses são mecanismos de coerção e indicam reanálise semântica. Mais uma vez, essa é uma previsão a ser testada. 
Não temos a menor dúvida de que há muito a ser desenvolvido para chegarmos a uma compreensão menos intuitiva da semântica de muito e do seu papel adverbial. Entendemos, no entanto, que essa seção mostra como é possível trilhar esse caminho. Resta ainda o problema da leitura de qualidade exemplificada abaixo:

\section{(22) Chape joga muito e lidera. (blogdojuca.uol.com.br)}

Há muitas questões aqui. Entre elas o fato de esse tipo de modificação ser restrito. Aparentemente, ela ocorre com certas atividades que são socialmente avaliadas pelo prisma do artístico - escrever (mas não ler), cozinhar (mas não comer), jogar futebol (mas não jogar bola na parede), dançar (mas não espernear), e possivelmente outras. A leitura de qualidade ocorre mesmo sem o advérbio (talvez com uma curva prosódica de exclamação). É razoável supor que há um advérbio na forma lógica. Assim, (2c) é uma abreviação, por assim dizer, de (23):

(23) João dançou muito bem.

Muito estaria operando sobre bem, que qualifica o evento. Assim como na operação com adjetivos muito nos dá um subconjunto dos indivíduos que estão na extensão positiva do predicado adjetival, com dançou bem podemos supor que muito toma a extensão positiva de dançar bem e retorna o subconjunto de eventos de dançar bem que é "muito", i.e., o conjunto do dançar muito bem.

\section{CONCLUSÃO}

Nosso objetivo neste artigo foi introduzir a Semântica de Delineação como uma ferramenta para entendermos a modificação adverbial com muito estendendo essa semântica para o domínio dos eventos. Do que sabemos essa é uma proposta original e embora certamente muito mais sugestiva do que explícita, ela é, até onde sabemos, a primeira tentativa de entender com mais detalhe como ocorre a chamada modificação adverbial de muito. Ela permite assim que novos modelos sejam avançados. Talvez a sua grande vantagem seja permitir entendermos porque um mesmo item lexical como muito pode ocorrer em diferentes posições com a mesma função e, ao mesmo tempo, abrir diferentes leituras. Em línguas como o inglês ou o francês é preciso optar por formas lexicais distintas, mas a modificação adverbial parece ser bem similar, com exceção da leitura de qualidade, presente apenas no PB. A única restrição imposta por muito é que o domínio seja estruturado em ordenamentos, que são dados pelo contexto e restritos gramaticalmente. A modificação dos nomes depende do ordenamento em somas; no adjetivo, as ordenações são dadas por posições em uma escala; enquanto que a modificação adverbial parece atuar o conjunto de eventos ordenados de acordo com algum padrão dado contextualmente: quantidade de eventos, duração dos eventos, qualidade dos eventos. Esperamos ter mostrado também que uma semântica para 
muito adverbial depende, em grande parte, de decidirmos o que denota o predicado sobre o qual ele opera - na linha do que sugere Doetjes (2007) para o beaucoup. Isto é, muito não cria estrutura interna no predicado, mas as leituras disponíveis dependem de como o domínio está estruturado e de diferentes fatores pragmáticos. Finalmente, uma grande lacuna da nossa análise é a ausência de uma discussão sintática menos superficial. Há, portanto, muito ainda a ser feito.

\section{$\overline{\text { REFERÊNCIAS }}$}

BACH, Emmon. The algebra of events. Linguistics and Philosophy, n. 9, vol. 1, pp. 5-16, 1986.

BALE, Alan.; BARNER, David. The interpretation of functional heads: using comparatives to explore mass/count distinction. Journal of Semantics, 26, pp. 217-252, 2009.

BASSO, Renato; ILARI, Rodolfo. Telicidade e Degree Achievements. Anais do 6. Encontro do CELSUL. 3 a 5 de nov de 2004. Universidade Federal de Santa Catarina, Florianópolis/SC. Disponível em: $<$ http://bit.ly/2EPdiJi $>$. Acesso em 03/01/2018.

BASSO, Renato; PIRES DE OLIVEIRA, Roberta. Generic and weak demonstratives: the realm of kinds. Journal of Portuguese Linguistics, 14(1), pp. 45-62, 2015.

BEVILÁQUA, Kayron; PIRES DE OLIVEIRA, Roberta. Brazilian Bare Phrases and Referentiality: Evidences from an Experiment. Letras, 90, pp. 253-275, 2014.

BURNETT, Heather. A delineation solution to the puzzles of absolute adjectives. Linguistics \& Philosophy, 37, pp. 1-39, 2014.

BURNETT, Heather. Comparison Across Domains in Delineation Semantics. Journal of Logic, Language and Information. 24, pp. 233-265, 2015.

CHIERCHIA, Gennaro. Plurality of mass nouns and the notion of 'semantic parameter'. In: ROTHSTEIN, S. (Org.). Events and grammar. Dordrecht: Kluwer, 1998. pp. 53-103.

CHIERCHIA, Gennaro. Semântica. Trad. R. Ilari, L. Negri, L. A. Pagani. Londrina: EDUEL; Campinas: Editora da Unicamp, 2003.

CHIERCHIA, Gennaro. Mass nouns, vagueness and semantic variation. Synthese n. 174, p. 99-149, 2010.

DAVIDSON, Donald. The logical form of action sentences. In: RESCHER, N. (org.) The logic of decision and action. Pittsburg: University of Pittsburg Press, 1967.

DOETJES, Jenny. Quantifiers and selection: on the distribution of quantifying expressions in French, Dutch and English. PhD dissertation. Leiden University, 1997.

DOETJES, Jenny. Adverbs and quantification: degree versus frequency. Lingua, 117, pp. 685-720, 2007.

GUIMARÃES, M. R. Dos intensificadores como quantificadores. Tese (Doutorado em Letras). Universidade Federal do Paraná, Curitiba, 2007. 
ILARI, Rodolfo et alii. Considerações sobre a ordem dos advérbios. In: CASTILHO, Ataliba Teixeira de (org.). Gramática do português falado I: a ordem. Campinas/São Paulo: Editora da UNICAMP/FAPESP, 1993. pp. 65-140.

KAMP, Hans. Two theories about adjectives. In: KEENAN, E. (org.). Formal semantics of natural language. Cambridge: Cambridge University Press, 1975. pp. 123-155.

KENNEDY, C. Projecting the adjective. PhD Dissertation. University of California at Santa Cruz, 1997.

KENNEDY, C. Vagueness and grammar: the semantics of relative and absolute gradable adjectives. Linguistics and Philosophy, 30(1), pp. 1-45, feb. 2007.

KENNEDY, C.; LEVIN, B. Measure of change: the adjectival core of degree achievements. In: MCNALLY, L.; KENNEDY, C. (orgs.). Adjectives and adverbs: syntax, semantics and discourse. Oxford University Press, 2008. pp. 156-182.

KLEIN, Ewan. A semantics for positive and comparative adjectives. Linguistics and Philosophy 4, pp. 1-45, 1980.

KLEIN, Ewan. The interpretation of adjectival, nominal and adverbial comparatives. In: GROENENDIJK, J.A.G.; JANSSEN, T.M.V.; STOKHOF, M.B.J. (orgs.) Formal methods in the study of language. Amsterdam: Matematisch Centrum, 1981. pp. 381-398.

KRIFKA, M. Nominal reference, temporal constitution and quantification in event semantics. In: BARTSCH, R.; VAN BENTHEM, J; VAN EMDE BOAS, P. (orgs.). Semantics and contextual expression. Dordrecht: Foris, 1989. pp. 75-115.

KRIFKA, M. Four thousand ships passed through the lock: object-induced measure functions on events. Linguistics and Philosophy, n. 13, pp. 487-520, 1990.

LANDMAN, Fred. Events and Plurality. Kluwer Academic Publishers, Dordrecht, 2000.

LANDMAN, Fred; ROTHSTEIN, Susan 2012. The felicity of aspectual for-phrases Part I: Homogeneity. Language and Linguistics Compass 6/2, pp. 85-96, 2012.

MITTWOCH, Anitta. Aspects of the English aspect: on the interaction between perfect, progressive and durational phrases. Linguistics and Philosophy, vol. 11, n. 2, pp. 203-254, may 1988.

MÜLLER, Ana L. Genericity and the denotation of common nouns in Brazilian Portuguese. D.E.L.T.A, n.18, pp. 287-308, 2002.

PARSONS, T. Events in the Semantics of English. Cambridge, MA: MIT Press, 1990.

PIRES DE OLIVEIRA, Roberta; ROTHSTEIN, Susan. Bare Singular noun phrases are mass in Brazilian Portuguese. Lingua, 121, pp. 2153-2175, 2011.

PIRES DE OLIVEIRA, Roberta; SOUZA, Luisandro M. O singular nu e a comparação: uma proposta de derivação semântica. LinguíStica, vol. 9, n. 1, pp. 31-54, jun. de 2013.

PIRES DE OLIVEIRA, Roberta; BASSO, Renato; SOUZA, Luisandro M. 'O João fuma mais do que o Pedro’: um exercício de análise semântica. Revista do GEL, Araraquara, n. 4, pp. 105-128, 2007.

PIRES DE OLIVEIRA, Roberta. Dobras e redobras do Singular Nu: consturando a semântica através das Linguas. Porto Alegre: EDIPUCRS, 2014. 
QUADROS GOMES, Ana Paula. Uma proposta de distinção semântica para os intensificadores 'muito' e ‘bem'. Estudos Linguísticos, v. 40, n. 1, pp. 379-394, 2011.

QUADROS GOMES, Ana Paula. Uma explicação semântica para a distribuição do advérbio baixo 'muito'. (neste volume)

ROTHSTEIN, S. Structuring Events: a study in the semantics of lexical aspect. Oxford: Blackwell, 2004

ROTHSTEIN, S. Counting and the mass count distinction. Journal of Semantics, 27.3, pp. 343-397, 2010.

ROTHSTEIN, S. Counting in the verbal domain. Letras, n. Especial, v. 96: Linguística Formal, pp. 309-333, jul/dez 2017. 